\title{
Chronic pain and depression as factors associated with temporomandibular dysfunction in older adults with Parkinson's disease
}

\author{
Patrícia Fernanda Faccio ${ }^{1}$ \\ https://orcid.org/0000-0001-5431-541X \\ Raíssa Barreto Tavares ${ }^{2}$ \\ https://orcid.org/0000-0002-6993-0391 \\ Nadja Maria Jorge Asano ${ }^{3}$ \\ https://orcid.org/0000-0003-3644-7333 \\ Amdore Guescel C Asano 3 \\ https://orcid.org/0000-0002-3952-830X \\ Maria das Graças Wanderley de Sales Coriolano' \\ https://orcid.org/0000-0002-7937-7761 \\ Carla Cabral dos Santos Accioly Lins ${ }^{1}$ \\ https://orcid.org/0000-0002-1018-5331
}

Universidade Federal de Pernambuco UFPE, Programa de Pós-Graduação em Gerontologia, Recife, Pernambuco, Brasil.

2 Universidade Federal de Pernambuco UFPE, Curso de Graduação de Odontologia, Recife, Pernambuco, Brasil.

${ }^{3}$ Universidade Federal de Pernambuco UFPE, Hospital das Clínicas, Recife, Pernambuco, Brasil.

Conflict of interests: Nonexistent

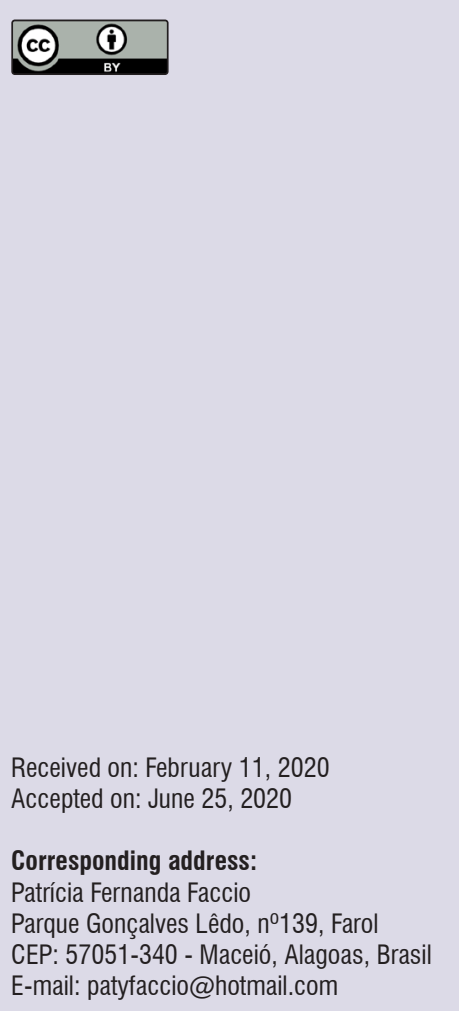

\section{ABSTRACT}

Purpose: to investigate whether chronic pain and depression are factors associated with temporomandibular dysfunction (TMD) in older adults with Parkinson's disease.

Methods: a cross-sectional study using the Research Diagnostic Criteria for Temporomandibular Disorders questionnaire. The clinical variables studied were chronic pain, depression, nonspecific physical symptoms including and excluding items of pain, and dentures use. The associations between the dependent and independent variables were evaluated by the chi-square odds ratio, with a 95\% confidence interval.

Results: a total of 81 older adults met the eligibility criteria - $67 \%$ were males, $74 \%$ were married or had a partner, $43 \%$ reported earning 1 to 2 minimum wages, and $47 \%$ were in the moderate stage of Parkinson's disease. TMD was identified in $22 \%$ of the sample, $12 \%$ reporting chronic pain. The statistical analysis showed an association between TMD and chronic pain ( $p=0.001,0 R=$ inf, $95 \% \mathrm{Cl}=12.13-$ inf) and between TMD and moderate-to-severe depression $(\mathrm{p}=0.014, \mathrm{OR}=4.8,95 \% \mathrm{Cl}=$ $1.14-23.51)$.

Conclusion: it was verified that chronic pain and moderate-to-severe depression were the factors associated with TMD in older adults presented with Parkinson's disease.

Keywords: Parkinson's Disease; Aged; Temporomandibular Joint Disorders; Chronic Pain; Depression 


\section{INTRODUCTION}

The morphophysiological changes that take place in the organism in the aging process affect the stomatognathic system (SS), which comprises the maxilla, mandible, dental arches, soft tissues (salivary glands, nerves, and blood vessels), masticatory muscles, and the temporomandibular joint (TMJ) ${ }^{1}$. Disorders in one of these parts can cause temporomandibular joint dysfunction (TMD), defined as a heterogeneous set of musculoskeletal alterations. It includes mandible dysfunction with or without pain, usually related to the masticatory muscles, TMJ, and associated structures ${ }^{2,3}$.

The population ages quickly in a process of inevitable changes in the epidemiologic transition. Simultaneously, there is an increase in the prevalence of neurodegenerative diseases, such as Parkinson's disease (PD) - which results from the loss of brain cells that produce dopamine and leads to progressive motor function disorders. Its main symptoms are limb, mandible, and face tremor, rigidity, bradykinesia, and postural instability. There may be other symptoms, including depression, emotional alterations, difficulty to swallow, chew, and speak, urinary problems, constipation, skin problems, and sleep interruptions ${ }^{4}$.

PD is universally distributed, affecting all ethnic groups and socioeconomic classes, as well as both genders, with slight predominance among males. Is the second most common neurodegenerative disorder ${ }^{5}$ and, although its cause remains unknown, it is believed to be related to an interaction between genetics and environmental factors ${ }^{6}$. In Brazil, the estimated prevalence is of 100 to 200 thousand cases $^{7}$; a populationbased study identified its prevalence to be $3.3 \%$ among people older than 60 years ${ }^{8}$.

The progression of PD is associated with increasingly limiting deficits, which indicate the person's general condition. Its classification follows HY disability scale, with degrees ranging from 1 to $5^{9}$, namely: $1-$ mild stage (independent: unilateral manifestations - tremor, rigidity, and bradykinesia), 2-3 - moderate stages (independent: bilateral manifestations - stooped posture, gait alterations, and the possibility of speech abnormalities), 4-5 - severe stages (dependent: they need help and are confined to a wheelchair or bed).

Psychosocial factors such as intensified pain, stress, and anguish are significantly more prevalent in individuals with TMD in comparison with healthy individuals ${ }^{10,11}$. A search in scientific databases for an integrative review on factors associated with temporomandibular dysfunction in older adults ${ }^{12}$ revealed the scarcity of studies in this field relating temporomandibular dysfunction, older adults, and Parkinson's disease. Therefore, the present study aimed to investigate whether chronic pain and depression are factors associated with TMD in older adults with Parkinson's disease, and which clinical diagnosis is most prevalent in the population studied.

\section{METHODS}

This study was approved by the Human Research Ethics Committee of the Universidade Federal de Pernambuco - UFPE, Brazil, complying with resolution no. 466/12, under evaluation report CAAE: 81081317.8.0000.5208. All the participants signed the informed consent form (ICF).

This cross-sectional study followed the STROBE statement checklist for observational studies ${ }^{13}$. It was conducted with older adults ( $\geq 60$ years) with PD, receiving care at the neurology outpatient center of the Hospital das Clínicas da Universidade Federal de Pernambuco (HC-UFPE), in a partnership with UFPE's Pro-Parkinson's Outreach Program, in Recife, Pernambuco, Brazil, from February to August 2018. The inclusion criteria were people: 1) with a clinical diagnosis of idiopathic PD in HY stages 1 to $3^{9} ; 2$ ) of both genders; 3 ) in the on-phase of antiparkinsonian drugs; 4) with teeth or using dentures; and 5) not disoriented, having their autonomy preserved. Older adults as follows were excluded: 1 ) those with another neurological disease associated with PD; 2) with face or mandible trauma; 3) with cognitive impairment assessed as unsatisfactory with the Mini-Mental State Examination (MMSE) ${ }^{14}$; 4) lacking teeth in one of the arches, or without dentures; 5) having undergone PD surgery; and 6) those who could not communicate orally.

The dependent variable was the TMD, while the verified independent clinical ones were chronic pain, depression, nonspecific physical symptoms (NPS) including and excluding pain items, and dentures use. The data was collected with questions based on the Research Diagnostic Criteria for Temporomandibular Disorders (RDC/TMD), translated and validated for use in Brazil ${ }^{15}$.

For the data collection, the interviewers first made contact with the older adults while they were in the neurologist's waiting room. They were invited to a separate room, where the initial information on the research was given to them. After they consented, they were evaluated regarding the eligibility criteria 
and then, with the MMSE ${ }^{16}$ with a cutoff score specific for older adults, according to their schooling level ${ }^{14}$; then, the RDC/TMD was administered ${ }^{15}$. The participants were taking routine PD medications, levodopa or dopaminergic agonists, or both, as prescribed by the physician.

The MMSE was the instrument used for cognitive screening. It assesses five cortical functions, as follows: temporal and spatial orientation (10 points); immediate memory (three points); attention and calculating (five points); evocation (three points); and language (nine points). Its maximum score is 30 points, and it takes five to 10 minutes to be administered ${ }^{16}$. The specific cutoff score for the older population depends on their years of schooling ${ }^{14}$ : illiterates -0 years (cutoff: 13 ); low schooling level -1 to 4 years, unfinished; medium schooling -4 to 8 years, unfinished (low and medium schooling level: cutoff: 18); High schooling level -8 years or more (cutoff: 26). For the classification, the highest grade they attended was considered, instead of the number of years at school, following what is referred to in the cutoff.

The TMD was assessed with the RDC/TMD, which is the gold standard for this type of assessment. It is composed of two axes: Axis I-measurement of physical findings - which consists of a clinical intra- and extraoral examination (mandibular movements, sounds, palpation of the TMJ and its muscles), and Axis II Psychosocial assessment - comprising 31 questions. To conduct the TMD diagnosis, the axes were interrelated, which enables the individuals to be classified in three groups: I - muscular diagnosis (presence of myofascial pain with limited TMJ opening); II - disk displacement (disk displacement with reduction, disk displacement without reduction with a limited opening, and disk displacement without reduction and without limited opening); III - Arthralgia, arthritis, osteoarthritis (TMJ arthralgia, arthritis, and osteoarthritis). Each person can present one or multiple diagnoses ${ }^{17}$.

In the data collection, the chronic pain score was classified in five degrees: Degree 0 - low intensity (without TMD-related pain in the last six months), Degree I - low intensity (pain intensity $<50$ points for incapacity according to the RDC, and less than three points for incapacity), Degree II - high intensity (pain intensity $>50$ points for incapacity according to RDC, and less than three points for incapacity), Degree III - moderate limitation (3 to 4 points for incapacity, regardless of the characteristic pain intensity), and Degree IV - severe limitation (5 to 6 points for incapacity, regardless of the characteristic pain intensity). However, for the statistical analysis of the pain, it was considered the presence of pain gathering the degrees I, II, III, and IV.

The degree of depression was classified as: Normal - lower than or equal to 0.535 , Moderate - higher than 0.535 and lower than 1.105, and Severe - equal to or higher than 1.105. The NPS including items of pain were classified as: Normal - lower than or equal to 0.5 , Moderate - higher than 0.5 and lower than 1.0, and Severe - equal to or higher than 1.0. The NPS excluding items of pain were classified as: Normal - lower than or equal to 0.428 , Moderate - higher than 0.428 and lower than 0.857 , and Severe - equal to or higher than 0.857 . Dentures use was classified as yes or no.

The sample calculation was based on the number of people enrolled in the Pro-Parkinson's Outreach Program - the total was 309 individuals with PD, of whom 241 were 60 years old or more. The sampling strategy calculated the following parameters: 95\% confidence interval, precision $5 \%$, alpha $5 \%$, and beta $20 \%$. The results led to a sample of 124 potentially eligible people; the expected TMD proportion in PD was $20,33 \%^{18}$.

\section{Examiners' training}

The individuals were interviewed by two examiners (a dental surgeon and a physical therapist) previously trained to ensure uniformity in data collection. The training involved an RDC/TMD administration course, which took place on September 22, 23, and 24, 2017, in Recife, Brazil, with a specialist in the field, with practical training of the questions and physical examination of the questionnaire, as well as the MMSE. The questionnaires were administered as interviews, and the questions were always read in the same sequence, along with the options to answer each question. After passing through the eligibility criteria, only the eligible ones underwent the RDC/TMD.

\section{Statistical analysis}

The data collected from the questionnaires were saved in an Excel spreadsheet, using descriptive statistics and frequency count to characterize the sample. The sample was stratified according to the diagnosis of the presence or not of TMD and its association with the clinical variables: the degree of chronic pain, degree of depression, NPS, including or excluding items of pain, and dentures use. The chi-square $\left(X^{2}\right)$ odds ratio (OR) with a $95 \%$ confidence 
interval $(\mathrm{Cl})$ was used in the analysis, processed on Statistica 13.2 software, with a $5 \%$ significance level. For the association between TMD and the clinical variables, the following analyses were employed: sensitivity, specificity, positive predictive value (PPV), negative predictive value (NPV), and degree of agreement with the Kappa coefficient to assess the accuracy of the associated variables.

The sensitivity was considered as the capacity of the clinical variables to correctly identify those with TMD; and the specificity was considered as the capacity of the clinical variables, when absent, to discard TMD. The PPV indicated the proportion of people with TMD among those who had a positive test of the variables; and the NPV showed the proportion of healthy people (without TMD) among those with a negative test of the variables. The greater the prevalence of the disease in the population tested, the higher is the PPV and the lower the NPV; the lower the prevalence of the disease in the population tested, the lower the PPV and the higher the NPV.

The Kappa coefficient was used to assess the degree of agreement between the clinical variables and the TMD diagnosis, characterizing it as an association measure used to describe and test the degree of agreement (reliability and precision) in the TMD classification. The different levels of agreement are: < zero: no agreement; zero - 0.20: minimum agreement; 0.21 - 0.40: reasonable agreement; $0.41-0.60$ : moderate agreement; $0.61-0.80$ : substantial agreement; $0.81-$ 1.0: perfect agreement ${ }^{19}$.

\section{RESULTS}

A total of 124 older adults with Parkinson's disease were invited to participate in this research. Of those, 81 met the eligibility criteria and comprised the final sample (Figure 1).

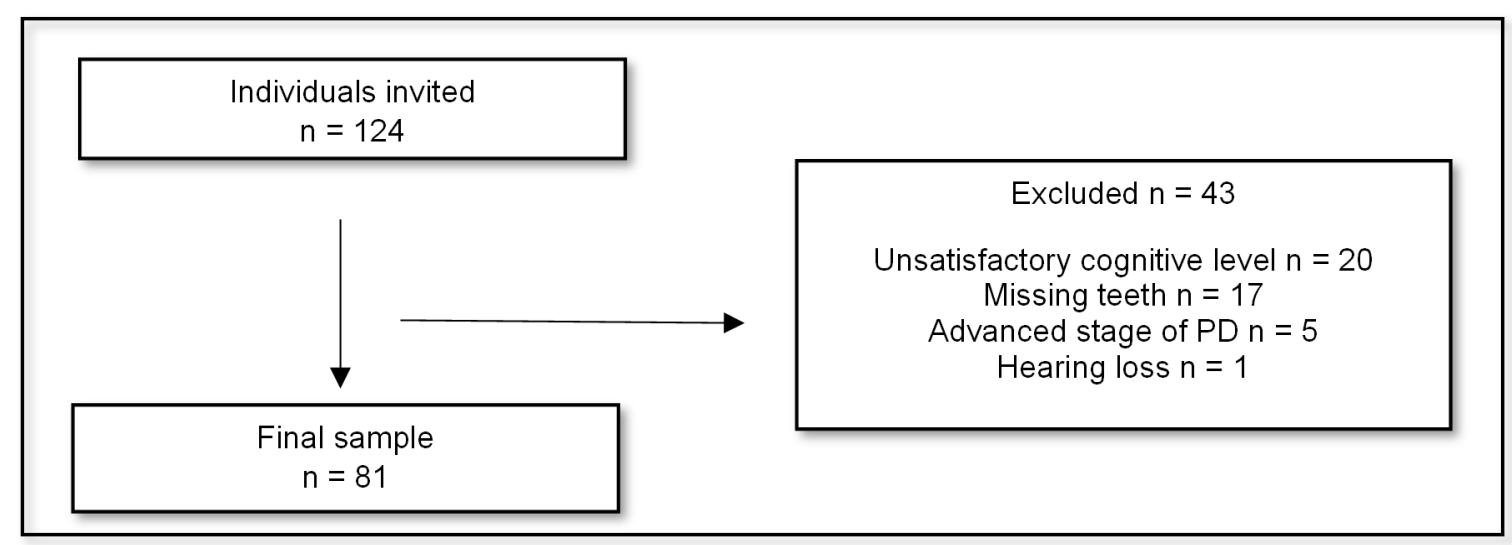

Figure 1. Flowchart with the selection of the final sample

The sociodemographic characteristics of the sample are given in Table 1, as well as the PD stages in older adults. The age ranged from 60 to 89 years ( \pm 69 ); $67 \%$ were males, and $27 \%$ had schooling level between 5 and 8 years; $74 \%$ were married or had a partner; $43 \%$ stated an income of 1 to 2 minimum wages; and $47 \%$ of the older adults were in the moderate stage of PD (HY 2-3). 
Table 1. Sociodemographic characteristics and stage of Parkinson's disease in older adults, Recife, PE, Brazil, 2018

\begin{tabular}{|c|c|c|}
\hline Variables & $\mathbf{N}=81$ & Frequency (\%) \\
\hline \multicolumn{3}{|l|}{ Age } \\
\hline $60-69$ years & 42 & $52 \%$ \\
\hline $70-79$ years & 35 & $43 \%$ \\
\hline 80 years or more & 4 & $5 \%$ \\
\hline \multicolumn{3}{|l|}{ Gender } \\
\hline Males & 54 & $67 \%$ \\
\hline Females & 27 & $33 \%$ \\
\hline \multicolumn{3}{|l|}{ Schooling level } \\
\hline Illiterate & 5 & $6 \%$ \\
\hline $1-4$ years at school & 20 & $25 \%$ \\
\hline $5-8$ years at school & 22 & $27 \%$ \\
\hline $9-11$ years at school & 17 & $21 \%$ \\
\hline $12-17$ years at school & 17 & $21 \%$ \\
\hline \multicolumn{3}{|l|}{ Marital status } \\
\hline Married or has a partner & 60 & $74 \%$ \\
\hline Separated or divorced & 6 & $7 \%$ \\
\hline widow/widower & 9 & $11 \%$ \\
\hline single & 5 & $6 \%$ \\
\hline \multicolumn{3}{|l|}{ Income (MW)* } \\
\hline Less than 1 & 5 & $6 \%$ \\
\hline From 1 to 2 & 35 & $43 \%$ \\
\hline From 3 to 5 & 29 & $36 \%$ \\
\hline From 6 to 10 & 7 & $9 \%$ \\
\hline From 11 to 20 & 3 & $4 \%$ \\
\hline Could not inform & 2 & $2 \%$ \\
\hline \multicolumn{3}{|c|}{ Stages of Parkinson's disease } \\
\hline Mild stage 1 & 20 & $25 \%$ \\
\hline Moderate stages 2 and 3 & 60 & $74 \%$ \\
\hline
\end{tabular}

${ }^{*} \mathrm{MW}=$ Minimum wage in Brazil, in $2018 \mathrm{R} \$ 954,00$.

The presence of TMD was identified in $22 \%$ of the older adults. Regarding the degree of chronic pain, $12 \%$ reported pain and had TMD, and $58 \%$ had moderate to severe depression. The NPS including or excluding items of pain was considered severe in
$36 \%$ and $44 \%$ of the sample, respectively; $43 \%$ used dentures (Table 2).

Those diagnosed with TMD were distributed according to the RDC/TMD groups; Group II (disk displacement) was the most prevalent) (Figure 2). 
Table 2. Distribution of the temporomandibular dysfunction and the clinical variables: the degree of chronic pain, degree of depression, nonspecific physical symptoms including items of pain, nonspecific physical symptoms excluding items of pain, and dentures use, Recife, PE, Brazil, 2018

\begin{tabular}{lcc}
\hline Variables & $\mathbf{N = 8 1}$ & Frequency (\%) \\
\hline Temporomandibular Dysfunction & 18 & $22 \%$ \\
Presence & 63 & $88 \%$ \\
Absence & 71 & $88 \%$ \\
\hline Degree of Chronic Pain & 7 & $9 \%$ \\
Degree 0 & 2 & $2 \%$ \\
Degree I & 0 & $0 \%$ \\
Degree II & 1 & $1 \%$ \\
Degree III & & \\
Degree IV & 34 & $42 \%$ \\
\hline Degree of Depression & 28 & $35 \%$ \\
Normal & 19 & $23 \%$ \\
Moderate & & $41 \%$ \\
Serious / Severe & 33 & $23 \%$ \\
\hline NPS including items of pain* & 19 & $36 \%$ \\
Normal & 29 & $36 \%$ \\
Moderate & & $20 \%$ \\
Serious / Severe & 29 & $44 \%$ \\
\hline NPS excluding items of pain * & 16 & \\
Normal & 36 & $43 \%$ \\
Moderate & & $57 \%$ \\
Serious / Severe & 35 & \\
\hline Dentures use & 46 & \\
Yes & & \\
No & & \\
\hline
\end{tabular}

*NPS: nonspecific physical symptoms including or excluding items of pain.

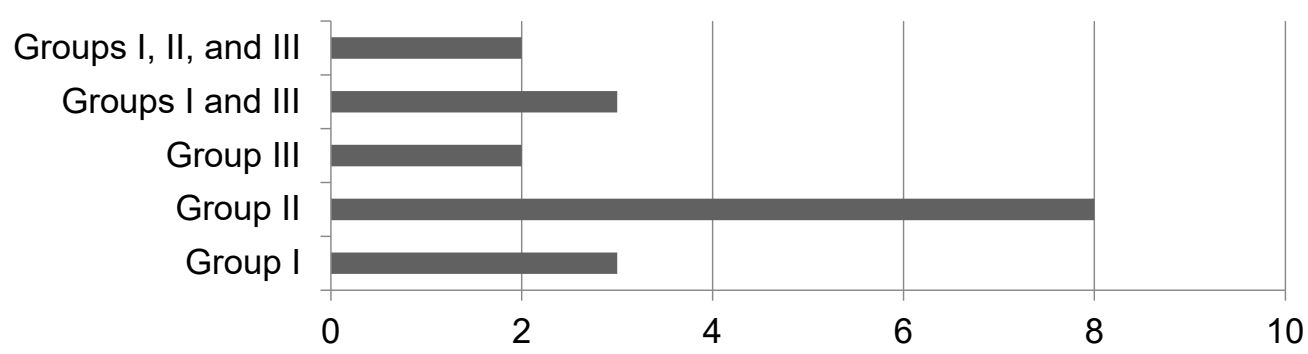

Figure 2. Distribution of the presentation of the number of older adults, according to the dysfunction by the groups of the Research Diagnostic Criteria for Temporomandibular Disorders questionnaire

The association between TMD diagnosis and the clinical variables: chronic pain, depression, NPS including items of pain, NPS excluding items of pain, and dentures use are shown in Table 3. There was a significant association with chronic pain $(p=0.001)$ and moderate and severe depression $(p=0.014)$ (Table 3). 
Table 3. Association of the clinical diagnosis of temporomandibular joint dysfunction with the clinical variables: chronic pain, depression, nonspecific physical symptom including items of pain, nonspecific physical symptom excluding items of pain, and dentures use, Recife, PE, Brazil, 2018

\begin{tabular}{|c|c|c|c|c|c|}
\hline Variables & & With TMD & Without TMD & Total & \\
\hline \multirow{8}{*}{ Chronic Pain } & & & & & $p$-value $=0.001$ \\
\hline & With pain & 10 & 0 & 10 & $\mathrm{OR}=\mathrm{inf}$ \\
\hline & & & & & $95 \% \mathrm{Cl}=12.13-\mathrm{inf}$ \\
\hline & Without pain & 8 & 63 & 71 & Kappa $=0.66$ \\
\hline & & & & & Sens $=0.55$ \\
\hline & & & & & Spe $=1.00$ \\
\hline & Total & 18 & 63 & 81 & $\mathrm{PPV}=1.00$ \\
\hline & & & & & $\mathrm{NPV}=0.88$ \\
\hline \multirow{8}{*}{ Depression } & & & & & $p$-value $=0.014$ \\
\hline & With depression & 15 & 32 & 47 & $\mathrm{OR}=4.8$ \\
\hline & & & & & $95 \% \mathrm{Cl}=1.14-23.51$ \\
\hline & Without depression & 3 & 31 & 34 & Kappa $=0.207$ \\
\hline & & & & & Sens $=0.83$ \\
\hline & & & & & Spe $=0.49$ \\
\hline & Total & 18 & 63 & 81 & $\mathrm{PPV}=0.31$ \\
\hline & & & & & $N P V=0.91$ \\
\hline \multirow{3}{*}{$\begin{array}{l}\text { NPS including items } \\
\text { of pain }\end{array}$} & Yes & 13 & 35 & 48 & $p$-value $=0.20$ \\
\hline & No & 5 & 28 & 33 & $\mathrm{OR}=2.00$ \\
\hline & Total & 18 & 63 & 81 & $95 \% \mathrm{Cl}=0.59-7.67$ \\
\hline \multirow{3}{*}{$\begin{array}{l}\text { NPS excluding } \\
\text { items of pain }\end{array}$} & Yes & 14 & 28 & 52 & $p$-value $=0.17$ \\
\hline & No & 4 & 25 & 29 & $\mathrm{OR}=2.3$ \\
\hline & Total & 18 & 63 & 81 & $95 \% \mathrm{Cl}=0.6-9.4$ \\
\hline \multirow{3}{*}{ Dentures use } & With dentures & 6 & 29 & 35 & $p$-value $=0.33$ \\
\hline & Without dentures & 12 & 34 & 46 & $\mathrm{OR}=0.58$ \\
\hline & Total & 18 & 63 & 81 & $95 \% \mathrm{Cl}=0.16-1.97$ \\
\hline
\end{tabular}

Legend: TMD = temporomandibular dysfunction; NPS = nonspecific physical symptom; OR = Odds Ratio; Cl = confidence interval; Kappa = Kappa coefficient; Sens $=$ sensitivity; Spe = specificity; PPV = positive predictive value; NPV = negative predictive value; ${ }^{\star} \mathrm{p}<0.05$.

\section{DISCUSSION}

There are few investigations regarding TMD in older adults with PD. It was observed in this research the presence of the dysfunction in $22 \%$ of the sample. These data corroborate a recent study that assessed the presence of TMD in people with PD aged 50 to 75 years, with a frequency of $23.8 \%^{20}$. It is difficult to diagnose TMD in older adults because the symptoms are simultaneous with age-related biochemical and physiological alterations ${ }^{21}$, which could increase its prevalence in this age group ${ }^{22,23}$. Regarding age, it was verified that older people tend to develop more resilience in the stomatognathic system, helping them better adjust to the alterations that come with aging ${ }^{24,25}$.

In this study, there was a predominance of males. Such a situation is not observed in studies with TMD, most of which encompass women. They are more likely to have associated comorbidities, such as fibromyalgia, irritable bowel syndrome, depression, and stress ${ }^{26-28}$. As for PD, some studies point to the predominance of males, which justifies the result obtained ${ }^{29,30}$.

According to Jankovic ${ }^{31}$ and De Lau, Breteler ${ }^{32}$, individuals with PD have motor impairments that can cause alterations in the stomatognathic system. A study identified a deficit in the control and speed of mandible movement in individuals with $\mathrm{PD}^{33}$. Another one assessed the function and oral health of older adults with PD and the results revealed temporomandibular joint dysfunction, and unsatisfactory chewing and mandible opening, causing a negative impact on these individuals' oral health ${ }^{34}$. 
Regarding the PD stages, most of the interviewees were in the moderate stage (HY 2-3), corroborating research that investigated people with PD and TMD and found similar results ${ }^{35}$.

Research conducted by Magalhães et al ${ }^{36}$ studied the influence of socioeconomic and demographic factors in the occurrence of TMD, and verified that people in the lower-middle and lower classes are 4.35 times more likely to develop myofascial pain and 11.3 times more likely to have joint problems - poverty is an important condition leading to this situation. Sampaio et al. ${ }^{27}$ analyzed the factors associated with TMD in the institutionalized and noninstitutionalized older population in Feira de Santana, Bahia, Brazil. The noninstitutionalized older population with TMD had a low schooling level (elementary school), similar to what was found in the present research, pointing out that most of the older adults had 5 to 8 years of schooling and finished only elementary school. As for marital status, most of them were widows or widowers, which disagrees with the present study, whose sample was mostly married or had a partner.

The degree of chronic pain was investigated with Axis II of the RDC/TMD. A significant association was verified between TMD and chronic pain ( $p=0.001$; OR $=$ inf; $95 \% \mathrm{Cl}=12.13$-inf) - the OR found an "inf" (infinite) result. This means that in the table where the variables were crossed, a zero was found, there were no people with the TMD or chronic pain, and the opposite verification was true, as all who had TMD also had chronic pain. This was confirmed by the specificity assessment, showing that all those who had chronic pain also had TMD. The Kappa was 0.66 and it expressed good reliability with a substantial agreement. Pain in TMD is frequently associated with other symptoms such as muscle and joint pains ${ }^{37}$.

Moderate-to-severe depression $(p=0.014$; OR $=$ 4.8; $95 \% \mathrm{Cl}=1.14-23.51$ ) was also associated with TMD. According to this study's investigation, older adults with depression are 4.8 more likely to have TMD when compared with those who do not have this pathology. It was assessed with Axis II: Psychosocial condition of the RDC/TMD ${ }^{15}$, with the following question: "In the last four weeks, how anguished or worried have you been?". It was followed by two sub-questions with specific scores. This variable presented weak precision (Kappa $=0.207)$, with a minimum agreement in relation to the dysfunction. The sensitivity in depression indicated that $83 \%$ of those with TMD had depression.
Psychological symptoms, such as depression, somatization, and anxiety in people with chronic pain associated with TMD are being investigated. Individuals with TMD are more depressive or anxious than asymptomatic individuals, and the symptoms of the dysfunction start in periods of psychological stress, growing more intense in situations of anxiety $^{38-40}$. This finding corroborates the study by Sampaio et al..$^{27}$, in which depression was the strongest predictor associated with the prevalence of TMD.

The NPS including and excluding items of pain and the denture use were not associated with TMD. The NPS including and excluding items of pain were considered severe. However, no studies were found in the literature with a similar association between the variables for discussion.

As for clinical diagnosis, Group II - disk displacement (characterized by the presence of clicking) prevailed, with eight older adults. Similar data was also found in research by Silva et al..$^{35}$, who assessed TMD in people with Parkinson's disease, corroborating the data from the present study.

Cross-sectional studies are inherently limited, as they enable only associations to be observed, not allowing conclusions to be drawn on causality - they reflect the situation in a given period. Hence, future research with older adults is warranted, involving other variables, enriching the discussion to establish other cause and effect relationships among older adults with $\mathrm{PD}$ and TMD.

\section{CONCLUSION}

In this study, a low occurrence of TMD was verified among older adults with Parkinson's disease. Group II (disk displacement) was the most prevalent of the clinical TMD diagnoses. The associated factors were chronic pain and depression (moderate to severe).

\section{ACKNOWLEDGMENT}

Gratitude is extended to José Luiz Ferreira Filho, Celso Jaco Faccio, and Maria Grassi Costa for their contribution by reading this manuscript and offering suggestions in its preparation. 


\section{REFERENCES}

1. Lund JP. Mastication and its control by the brain stem. Critical reviews in oral biology and medicine: an official publication of the American Association of Oral Biologists. Crit Rev Oral Biol Med. 1991;2(1):33-64.

2. Ohrbach R, Dworkin SF. The evolution of TMD diagnosis: past, present, future. Journal of dental research. J Dent Res. 2016;95(10):1093-101.

3. Lim PF, Smith S, Bhalang K, Slade GD, Maixner W. Development of temporomandibular disorders is associated with greater bodily pain experience. Clin J Pain. 2010;26(2):116-20.

4. Postuma RB, Berg D, Stern M, Poewe W, Olanow $\mathrm{CW}$, Oertel $\mathrm{W}$ et al. MDS clinical diagnostic criteria for Parkinson's disease. Mov Disord. 2015;30(12):1591-601.

5. Guo X, Song W, Chen K, Chen X, Zheng Z, Cao $B$ et al. Gender and onset age-related features of non-motor symptoms of patients with Parkinson's disease: a study from Southwest China. Parkinsonism Relat Disord. 2013;19(11):961-5.

6. Pringsheim $\mathrm{T}$, Jette $\mathrm{N}$, Frolkis $\mathrm{A}$, Steeves TD. The prevalence of Parkinson's disease: a systematic review and meta-analysis. Mov Disord. 2014;29(13):1583-90.

7. Barbieri FA, Rinaldi NM, Santos PC, Lirani-Silva E, Vitorio R, Teixeira-Arroyo $C$ et al. Functional capacity of Brazilian patients with Parkinson's disease (PD): relationship between clinical characteristics and disease severity. Arch Gerontol Geriatr. 2012;54(2):e83-8.

8. Barbosa MT, Caramelli P, Maia DP, Cunningham MC, Guerra HL, Lima-Costa MF et al. Parkinsonism and Parkinson's disease in the elderly: a community-based survey in Brazil (the Bambui study). Mov Disord. 2006;21(6):800-8.

9. Hoehn MM, Yahr MD. Parkinsonism: onset, progression and mortality. Neurology. 1967;17(5):427-42.

10. Slade GD, Ohrbach R, Greenspan JD, Fillingim RB, Bair E, Sanders AE et al. Painful Temporomandibular Disorder: decade of discovery from OPPERA Studies. J Dent Res. 2016;95(10):1084-92.

11. Fillingim RB, Slade GD, Diatchenko L, Dubner $R$, Greenspan JD, Knott $C$ et al. Summary of findings from the OPPERA baseline case-control study: implications and future directions. J Pain. 2011;12(11 Suppl):T102-7.
12. Faccio PF, Santos MAB, Silva TAM, Moretti EC, Coriolano MGWS, Lins CSA. Fatores associados à disfunção temporomandibular em pessoas idosas: uma revisão integrativa da literatura. Rev. Bras. Geriatr. Gerontol. 2019;22(1):e180116.

13. Malta M, Cardoso LO, Bastos Fl, Magnanini MM, Silva CM. STROBE initiative: guidelines on reporting observational studies. Rev. Saúde Pública. 2010;44(3):559-65.

14. Bertolucci PH, Brucki SM, Campacci SR, Juliano Y. The Mini-Mental State Examination in a general population: impact of educational status. Arq Neuropsiquiatr. 1994;52(1):1-7.

15. Dworkin SF, LeResche L. Research diagnostic criteria for temporomandibular disorders: review, criteria, examinations and specifications, critique. J Craniomandib Disord. 1992;6(4):301-55.

16. Folstein MF, Folstein SE, McHugh PR. "Mini-mental state". A practical method for grading the cognitive state of patients for the clinician. J Psychiatr Res. 1975;12(3):189-98.

17. de Lucena LB, Kosminsky M, da Costa LJ, de Goes PS. Validation of the Portuguese version of the RDC/TMD Axis II questionnaire. Brazilian oral research. 2006;20(4):312-7.

18. Silva PF, Biasotto-Gonzalez DA, Motta LJ, Silva SM, Ferrari RA, Fernandes KP et al. Impact in oral health and the prevalence of temporomandibular disorder in individuals with Parkinson's disease. J Phys Ther Sci. 2015;27(3):887-91.

19. Reed 3rd JF. Homogeneity of kappa statistics in multiple samples. Computer methods and programs in biomedicine. Comput Methods Programs Biomed. 2000;63(1):43-6.

20. Silva PF, Motta LJ, Silva SM, Ferrari RA, Fernandes KP, Bussadori SK. Computerized analysis of the distribution of occlusal contacts in individuals with Parkinson's disease and temporomandibular disorder. Cranio. 2016;34(6):358-62.

21. Petersen PE, Yamamoto T. Improving the oral health of older people: the approach of the WHO Global Oral Health Programme. Community Dent Oral Epidemiol. 2005;33(2):81-92.

22. Gaszynska E, Szatko F, Godala M, Gaszynski T. Oral health status, dental treatment needs, and barriers to dental care of elderly care home residents in Lodz, Poland. Clin Interv Aging. 2014;9:1637-44. 
23. Cornejo M, Perez G, de Lima KC, Casals-Peidro $\mathrm{E}$, Borrell $\mathrm{C}$. Oral health-related quality of life in institutionalized elderly in Barcelona (Spain). Med Oral Patol Oral Cir Bucal. 2013;18(2):e285-92.

24. Boscato N, Schuch HS, Grasel CE, Goettems ML. Differences of oral health conditions between adults and older adults: a census in a southern Brazilian city. Geriatr Gerontol Int. 2016;16(9):1014-20.

25. Manfredini D, Poggio CE. Prosthodontic planning in patients with temporomandibular disorders and/or bruxism: a systematic review. J Prosthet Dent. 2017;117(5):606-13.

26. Hoffmann RG, Kotchen JM, Kotchen TA, Cowley T, Dasgupta M, Cowley AW Jr. Temporomandibular disorders and associated clinical comorbidities. Clin J Pain. 2011;27(3):268-74.

27. Sampaio NM, Oliveira MC, Ortega AO, Santos LB, Alves TD. Temporomandibular disorders in elderly individuals: the influence of institutionalization and sociodemographic factors. CoDAS. 2017;29(2):e20160114.

28. Carlsson GE, Ekback G, Johansson A, Ordell S, Unell $L$. Is there a trend of decreasing prevalence of TMD-related symptoms with aging among the elderly? Acta Odontol Scand. 2014;72(8):714-20.

29. Savica R, Grossardt BR, Bower JH, Ahlskog $\mathrm{JE}$, Rocca WA. Time trends in the incidence of Parkinson's disease. JAMA neurology. 2016;73(8):981-9.

30. Collaborators GBDPsD. Global, regional, and national burden of Parkinson's disease, 1990-2016: a systematic analysis for the Global Burden of Disease Study 2016. Lancet Neurol. 2018;17(11):939-53.

31. Jankovic J. Parkinson's disease: clinical features and diagnosis. J Neurol Neurosurg Psychiatry. 2008;79(4):368-76.

32. de Lau LM, Breteler MM. Epidemiology of Parkinson's disease. Lancet Neurol. 2006;5(6):525-35.

33. Robertson LT, Hammerstad JP. Jaw movement dysfunction related to Parkinson's disease and partially modified by levodopa. J Neurol Neurosurg Psychiatry. 1996;60(1):41-50.

34. Bakke M, Larsen SL, Lautrup C, Karlsborg M. Orofacial function and oral health in patients with Parkinson's disease. Eur J Oral Sci. 2011;119(1):27-32.
35. Silva TVdA, Sobral AdV, Silva RMd, Almeida VLdS, Coriolano MdGWdS, Lins CCdSA. Pain, click and crepitation as factors associated with temporomandibular dysfunction in Parkinson's disease. Br J Pain. 2018;1 (3):248-54.

36. Magalhaes BG, de Sousa ST, de Mello VV, da-Silva-Barbosa AC, de Assis-Morais MP, Barbosa-Vasconcelos MM et al. Risk factors for temporomandibular disorder: binary logistic regression analysis. Med Oral Patol Oral Cir Bucal. 2014;19(3):e232-6.

37. Lorduy KM, Liegey-Dougall A, Haggard R, Sanders $\mathrm{CN}$, Gatchel RJ. The prevalence of comorbid symptoms of central sensitization syndrome among three different groups of temporomandibular disorder patients. Pain Pract. 2013;13(8):604-13.

38. Fillingim RB, Ohrbach R, Greenspan JD, Knott C, Dubner R, Bair E et al. Potential psychosocial risk factors for chronic TMD: descriptive data and empirically identified domains from the OPPERA case-control study. J Pain. 2011;12(11 Suppl):T46-T60.

39. Diracoglu D, Yildirim NK, Saral I, Ozkan M, Karan A, Ozkan $S$ et al. Temporomandibular dysfunction and risk factors for anxiety and depression. J Back Musculoskelet Rehabil. 2016;29(3):487-91.

40. Calixtre LB, Gruninger BL, Chaves TC, Oliveira AB. Is there an association between anxiety/depression and temporomandibular disorders in college students? J Appl Oral Sci. 2014;22(1):15-21. 